\title{
Does numerical processing uniquely predict first graders' future development of single-digit arithmetic? ${ }^{\text {is }}$
}

\author{
Kiran Vanbinst* ${ }^{*}$, Pol Ghesquière, Bert De Smedt* \\ Faculty of Psychology and Educational Sciences, Parenting and Special Education Research Unit, KU Leuven, Belgium
}

\section{A R T I C L E I N F O}

\section{Article history:}

Received 24 February 2014

Received in revised form 18 August 2014

Accepted 5 December 2014

Available online $\mathrm{xxxx}$

\section{Keywords:}

longitudinal design

numerical processing

arithmetic development

fact retrieval

\begin{abstract}
A B S T R A C T
The present longitudinal study investigated whether children's numerical processing skills at the start of formal schooling predict subsequent development in single-digit arithmetic and fact retrieval. At the start of first grade, we administered measures of numerical processing (digit naming, symbolic numerical magnitude comparison, nonsymbolic numerical magnitude comparison) as well as measures of intellectual ability, preschool mathematical abilities, working memory and processing speed. Our longitudinal data indicate that children's numerical processing skills at primary school entrance were predictively related to their future competence in singledigit arithmetic and their reliance on arithmetic fact retrieval. This association was not explained by children's intellectual ability, preschool mathematical abilities, verbal working memory, visual-spatial short-term memory and processing speed. These findings indicate that numerical processing skills precede children's development in single-digit arithmetic.
\end{abstract}

(c) 2014 Elsevier Inc. All rights reserved.
There is converging evidence that links proficient numerical processing skills, with higher mathematics achievement (De Smedt, Noël, Gilmore, \& Ansari, 2013) but this knowledge is largely based on crosssectional data. Such findings do not allow us to conclude whether numerical processing is a precursor of mathematics achievement. Only but a few longitudinal studies are currently available. These studies have reported consistent and predictive associations between symbolic numerical magnitude comparison (i.e. comparing Arabic digits) and children's future general mathematics achievement (e.g., De Smedt, Verschaffel, \& Ghesquière, 2009; Sasanguie, Van den Bussche, \& Reynvoet, 2012). Conflicting findings have been reported for the nonsymbolic numerical magnitude comparison (i.e. comparing dot arrays). While some studies observed that nonsymbolic magnitude comparison predict future general mathematics achievement (Libertus, Feigenson, \& Halberda, 2013a,b; Mazzocco, Feigenson, \& Halberda, 2011), others have failed to find such longitudinal association (Sasanguie et al., 2012). One possible explanation for this might be that the abovementioned studies investigated mathematical competence with broad general standardized mathematics achievement tests. These tests reflect performance averaged across various mathematical skills and it has been observed that numerical processing impacts more on some specific mathematical skills compared to others. For example,

\footnotetext{
This research was supported by grant G.0359.10 of the Research Foundation Flanders (FWO), Belgium. We would like to thank all participating children, parents and teachers.

* Corresponding authors at: Parenting and Special Education Research Unit, L. Vanderkelenstraat 32, box 3765, B-3000 Leuven, Belgium.

E-mail addresses: Kiran.Vanbinst@ppw.kuleuven.be (K. Vanbinst), Bert.DeSmedt@ppw.kuleuven.be (B. De Smedt).
}

Linsen, Verschaffel, Reynvoet, and De Smedt (2014) showed that in multi-digit subtraction, the use of the flexible subtraction-by-addition strategy relied more on numerical processing than the more common direct subtraction strategy (see also Fuchs, Geary, Fuchs, Compton, \& Hamlett, 2014; Jordan, Mulhern, \& Wylie, 2009).

Three longitudinal studies focused on one specific mathematical skill, i.e. arithmetic, and investigated how numerical processing predicted subsequent performance (Bartelet, Vaessen, Blomert, \& Ansari, 2014; Desoete, Ceulemans, De Weerdt, \& Pieters, 2010; Sasanguie, Göbel, Moll, Smets, \& Reynvoet, 2013). Desoete et al. (2010) found that nonsymbolic numerical magnitude comparison accuracy in preschool predicted arithmetic in first and second grade, independently of intellectual ability. Bartelet et al. (2014), however, demonstrated that preschool symbolic, but not nonsymbolic numerical magnitude comparison predicted first graders arithmetic, even when controlling for gender, intelligence and processing speed. Sasanguie et al. (2013) reported that the speed of comparing Arabic digits in the middle of first grade predicted arithmetic one year later, even after controlling for spelling achievement.

One limitation of these three longitudinal studies is that they did not account for children's mathematical abilities when they enter formal schooling. This is important because children have a good deal of mathematical knowledge before they receive formal mathematics instruction (Barth, Beckmann, \& Spelke, 2008; Resnick, 1989). For example, children intuitively learn from a very young age concepts such as absolute size (e.g., small, big) or part-whole relations and these early mathematical abilities emerge as reliable predictors of children's subsequent growth in mathematics (e.g., Aunola, Leskinen, Lerkkanen, \& Nurmi, 2004). A meta-analysis by Duncan et al. (2007) even pointed out that school-entry mathematical competence was the strongest predictor of 
children's future academic performance. Taking into account these preschool mathematical abilities will allow us to investigate whether there is a unique and robust predictive association between numerical processing at the onset of formal schooling and future competence in single-digit arithmetic, which was the aim of the current study.

The present study focuses on single-digit arithmetic up to 10 . This is because arithmetic comprises a major objective in the first grades of mathematics education and constitutes a building block for subsequent growth in mathematics (Kilpatrick, Swafford, \& Findell, 2001). Various studies have described how children develop strategies to solve single-digit arithmetic (e.g., Barrouillet, Mignon, \& Thevenot, 2008; Geary, 2013; Siegler, 1996). At first, children use counting to solve small additions and subtractions and these strategies are sometimes executed with additional support, such as fingers. Through repeated use of counting, children develop problem-answer associations or arithmetic facts, which are stored in their long-term memory (Siegler \& Shrager, 1984). Developing strong problem-answer associations is useful because solving arithmetic by directly retrieving facts is more efficient than using (time-consuming) counting strategies (e.g., Bailey, Littlefield, \& Geary, 2012). There are large individual differences in the acquisition and use of fact retrieval (Dowker, 2005) and these might be explained by variations in children's numerical processing skills.

Vanbinst, Ghesquière, and De Smedt (2012) have recently addressed this issue in a cross-sectional study in third graders. They showed for the first time that numerical processing was associated with individual differences in strategy use in single-digit arithmetic up to 20: Children who were more proficient in discriminating Arabic digits, but not dot arrays, retrieved more arithmetic facts from their memory and executed fact retrieval faster and more accurately. The data by Vanbinst et al. (2012) are, however, cross-sectional, and they do not allow us to infer whether numerical processing skills precede children's (growth in) single-digit arithmetic. We therefore aimed to investigate with a longitudinal design, whether numerical processing predicts first graders' future single-digit arithmetic. We specifically focused on the start of formal schooling, because we wanted to examine this association at the early stages of mathematics instruction and arithmetic fact development.

It should be noted that arithmetic fact development is also predicted by various non-numerical cognitive skills, such as verbal working memory, visuo-spatial short-term memory and processing speed (e.g., Bull, Espy, \& Wiebe, 2008; Holmes, Adams, \& Hamilton, 2008). Specifically, a recent meta-analysis by Friso-van den Bos, van der Ven, Kroesbergen, and van Luit (2013) highlighted that especially verbal working memory and visuo-spatial short-term memory were strongly associated with arithmetic. Verbal working memory supports the acquisition of arithmetic facts in early childhood (e.g., Barrouillet \& Lépine, 2005; Lefevre et al., 2013) and is crucial for keeping track of different steps during arithmetic problem solving (Imbo \& Vandierendonck, 2007a). Visuo-spatial short-term memory is particularly important during the early stages of learning arithmetic when children rely on (visuo-spatial) strategies such as finger counting (e.g., De Smedt et al., 2009; Rasmussen \& Bisanz, 2005). It is also important to point out that individual differences in both verbal working memory (Xenidou-Dervou, van Lieshout, \& van der Schoot, 2013) and visuo-spatial short-term memory (Caviola, Mammarella, Cornoldi, \& Lucangeli, 2012) have been related to measures of numerical processing in kindergarten. On the other hand, children's processing speed, which includes children's capacity to recall information from long-term memory, is associated with individual differences in arithmetic fact retrieval (e.g., Hecht, Torgesen, Wagner, \& Rashotte, 2001; Koponen, Aunola, Ahonen, \& Nurmi, 2007). Processing speed might also play an important role in numerical processing tasks, as these tasks are often analyzed in terms of reaction times. Because these non-numerical cognitive skills correlate with both arithmetic fact retrieval and numerical processing, these factors should be considered when investigating the association between numerical processing and arithmetic fact retrieval to determine whether numerical processing skills make independent contributions to later individual differences in single-digit arithmetic.

Against this background, the present longitudinal study investigated whether numerical processing skills at the onset of formal schooling uniquely predict future individual differences in single-digit arithmetic. The study comprised children who started primary school and who did not yet receive formal mathematics education. At the beginning of first grade, symbolic and nonsymbolic numerical magnitude comparison tasks were administered. We also included digit naming as an additional measure of symbolic processing. We subsequently evaluated their arithmetic skills and strategy use in the middle of first grade and at the start of second grade.

To carefully examine the unique predictive power of numerical processing on future individual differences in single-digit arithmetic we included a set of additional measures. First, participants completed a general curriculum-based standardized mathematics achievement test at primary school entrance, which evaluates children's mathematical abilities at the start of formal mathematics instruction. We also assessed three non-numerical cognitive predictors, i.e. verbal working memory, visuo-spatial short-term memory and processing speed. Non-numerical tasks were used in order to prevent task performance to be influenced by numerical processing. To rule out potential effects of intellectual ability, a measure of intelligence was also administered.

\section{Method}

\subsection{Participants}

Participants were typically developing children from three elementary schools in Flanders (Belgium). At the start of first grade (September 2011) the initial sample consisted of 88 participants. In the middle of first grade (February 2012) arithmetic data were available for 84 participants of the initial sample. At the start of second grade (September 2012) arithmetic data were available for 67 participants. We only included those participants whose arithmetic data were available at two subsequent time points, because we wanted to evaluate improvements in arithmetic over time. School absence, due to illness, at one or more time points or changing schools, led to missing data. This final sample $(n=67)$ comprised 38 girls and 29 boys ( $M_{\text {age }}$ at primary school entrance: 6 years and 2 months; $S D=3$ months). The participants came predominantly from middle- to upper middle-class families and their native language was Dutch. They had no history of developmental disorders and none had repeated a grade. Written informed parental consent was obtained for all participants.

\subsection{Materials}

Materials consisted of standardized tests, paper-and-pencil-tasks and computer tasks designed with the E-prime 1.0 software (Schneider, Eschmann, \& Zuccolotto, 2002).

\subsection{Numerical processing}

\subsubsection{Digit naming}

In the digit naming task, each of the numbers 1 to 9 was successively presented twice on the computer screen. The child was asked to name each digit. Reaction time (RT) was registered by a voice key, after which the answer was entered on the keyboard by the experimenter. There were two practice trials to make the child familiar with task administration.

\subsubsection{Numerical magnitude comparison}

Children's numerical magnitude processing skills were measured by means of symbolic and nonsymbolic numerical magnitude comparison tasks, consisting of Arabic digits and dot arrays, respectively. In these tasks children had to compare two simultaneously presented numerical 
magnitudes, one displayed on the left side of the computer screen, and one displayed on the right. Children had to indicate the larger of those two numerical magnitudes by pressing a key on the side of the larger one. They were instructed to perform both accurately and fast. Stimuli comprised all combinations of numerosities 1 to 9, yielding 72 trials for each task. In half of the trials the largest numerosity appeared on the left and in half of the trials the largest numerosity was presented on the right. Nonsymbolic stimuli were generated with the MATLAB script provided by Piazza, Izard, Pinel, Le Bihan, and Dehaene (2004) and were controlled for non-numerical parameters, such as dot size, total occupied area, and density, to minimize that decisions were dependent on non-numerical cues or perceptual features. A trial started with a $200 \mathrm{~ms}$ fixation in the center of the screen. After $1000 \mathrm{~ms}$, stimuli appeared and remained visible until the child responded, except for the nonsymbolic numerical magnitude comparison task, where the stimuli disappeared after $840 \mathrm{~ms}$, to avoid counting the number of dots. Each trial was initiated by the experimenter with a control key. RT and answers were registered by the computer. To familiarize children with the key assignments, three practice trials were included per task.

\subsection{Single-digit arithmetic}

Children's arithmetic skills were assessed with a single-digit addition and subtraction task. Stimuli were selected from the so-called standard set of single-digit arithmetic problems (Lefevre, Sadesky, \& Bisanz, 1996), which excludes tie problems (e.g., $3+3$ ) and problems containing 0 or 1 as operand or answer. Only small problems in which the solution remained below or equal to 10 were selected because children in the middle of first grade only received instruction in these problems. This resulted in a set of 14 problems per operation. Children were asked to perform both accurately and fast. Responses were verbal. A voice key registered the child's RT, after which the experimenter recorded the answer. Children could use whatever strategy they wanted to. On a trial-by-trial basis, the experimenter asked the children to verbally report the strategy they used. Similar to other studies in arithmetic (e.g., Imbo \& Vandierendonck, 2007b; Torbeyns, Verschaffel, \& Ghesquière, 2004), strategies were classified into retrieval (i.e., if the child immediately knew the answer and there was no evidence of overt calculations), procedure (i.e., if the child indicated that (s)he used counting or almost-doubling to arrive at the solution), or other (i.e., if the child did not know how (s)he solved the problem). This classification method is a valid and reliable way of assessing children's single-digit arithmetic strategy use (Siegler \& Stern, 1998). Two practice trials were presented to familiarize children with task administration.

\subsection{Additional measures}

\subsubsection{Preschool mathematical abilities}

Children's preschool mathematical abilities were assessed using a standardized general mathematics achievement test from the Flemish Student Monitoring System (Dudal, 2000). This untimed achievement test involves the number domain 1 to 10 and was developed to be assessed at the start of formal mathematics instruction. The test consists of 50 items, covering various aspects of mathematics: spatial concepts, counting, understanding of the meaning of ordinal numbers (e.g., first, second), magnitude comparison (e.g., understanding of the concepts less, more, and equal), word problem solving, measurement and mathematical language (e.g., understanding of concepts such as shortest, deeper, and higher). For each child, a standardized score $(M=100$, $S D=15)$ was calculated.

\subsubsection{Verbal working memory}

A listening span task from the working memory test battery for children (Pickering \& Gathercole, 2001), adapted to Dutch (e.g., De Smedt et al., 2009 for more elaborated task details), was used. In this nonnumerical task, children had to judge the correctness of a series of recorded sentences. They also had to memorize the last word in every sentence, and to recall those words in the presented order at the end of each trial.

\subsubsection{Visuo-spatial short-term memory}

The corsi block recall task from the working memory test battery for children (Pickering \& Gathercole, 2001) was used to assess children's visuo-spatial short-term memory (e.g., De Smedt et al., 2009 for more elaborated task details). For each trial, the experimenter tapped out a sequence, at a rate of one block per second, on a board with nine blocks. The child had to reproduce the sequence in the correct order.

\subsubsection{Processing speed}

Processing speed was evaluated with a rapid automatic naming task (van den Bos, Zijlstra, \& Van den Broeck, 2003), which involved the naming of colors. The presented test card consisted of 50 stimuli, with each stimulus (black, blue, red, yellow, and green) appearing 10 times. Prior to testing, the child was required to name the stimuli in the last column to determine whether the child was familiar with all the presented stimuli. The time to complete the card was recorded for each task.

\subsubsection{Intellectual ability}

Raven's Standard Progressive Matrices (Raven, Court, \& Raven, 1992) was administered as a measure of intellectual ability. For each child, a standardized score $(M=100, S D=15)$ was calculated.

\subsection{Procedure}

All participants completed the administered tasks individually in a quiet room at their own school, except for Raven's matrices and the general mathematics achievement test, which were group-based. At primary school entrance, all participants completed a standardized general mathematics achievement test. Digit naming, numerical magnitude comparison, verbal working memory, visuo-spatial short-term memory and processing speed skills were assessed at the start of first grade (September 2011). Intellectual ability was assessed in December 2011. Single-digit arithmetic was evaluated in the middle of first grade (February 2012) and at the start of second grade (September 2012).

\section{Results}

\subsection{Descriptive analyses}

\subsubsection{Cognitive skills at primary school entrance}

Table 1 presents the descriptive statistics of measures collected at the start of first grade. This table illustrates that the data were well distributed without ceiling or floor effects.

\subsubsection{Single-digit arithmetic}

Children's performance on the single-digit addition and subtraction tasks was evaluated in terms of accuracy, RT and the frequency of fact retrieval. Trials with incorrect responses or incorrect voice-key registrations ( $<2 \%$ of all trials) were not included in the RT and strategy use data. Trials deviating more than $3 S D$ s from the average participant's RT and trials with a RT below $500 \mathrm{~ms}$ ( $<0.5 \%$ of all trials) were excluded.

Fig. 1 presents the mean accuracy and RT for solving single-digit arithmetic per operation per time. A $2 \times 2$ repeated measures ANOVA with operation (addition vs. subtraction) and time (grade 1 vs. grade 2 ) as within-subject factors was conducted on accuracy and RT. A main effect of operation was observed: Additions were solved more accurately $\left(F(1,66)=18.19, p<.01, \eta^{2}=.22\right)$ and faster $(F(1,66)=9.99$, $\left.p<.01, \eta_{p}^{2}=.13\right)$ than subtractions. There was a main effect of time, indicating that both accuracy $\left(F(1,66)=60.19, p<.01, \eta^{2} p=.48\right)$ and RT $\left(F(1,66)=13.34, p<.01, \eta_{p}^{2}=.17\right)$ improved over developmental time. With regard to accuracy, operation interacted with time 
Table 1

Descriptive statistics of the measures collected at the start of first grade $(n=67)$.

\begin{tabular}{lrrrc}
\hline & M & SD & Range & $\begin{array}{l}\text { Maximum } \\
\text { possible }\end{array}$ \\
\hline Digit naming & & & & \\
$\quad$ Accuracy (\% correct) & 92.24 & 11.12 & $55-100$ & 100 \\
$\quad$ RT (ms) & 998.23 & 282.57 & $571.35-2029.92$ & \\
Symbolic numerical & & & & 100 \\
$\quad$ magnitude comparison & & & & \\
$\quad$ Accuracy (\% correct) & 88.50 & 7.74 & $58-97$ & 100 \\
$\quad$ RT (ms) & 1458.93 & 349.19 & $875.49-2423.46$ & \\
Nonsymbolic numerical & & & & \\
$\quad$ magnitude comparison & & & & \\
$\quad$ Accuracy (\% correct) & 82.34 & 8.54 & $58-99$ & \\
$\quad$ RT (ms) & 874.194 & 196.90 & $605.44-1811.32$ & \\
Preschool mathematical & 104.19 & 10.91 & $65.50-121.30$ & \\
$\quad$ abilities & & & & \\
Verbal working memory & 3.31 & 1.45 & $0-6$ & \\
Visuo-spatial short-term & 7.09 & 2.11 & $3-12$ & \\
$\quad$ memory & & & & \\
Processing speed (s) & 68.79 & 17.28 & $40-118$ & \\
Intellectual ability & 105 & 14.05 & $80-141$ & \\
\hline
\end{tabular}

Note. RT $=$ Reaction time.

$\left(F(1,66)=17.51, p<.01, \eta_{p}^{2}=.21\right)$. Post-hoc $t$-tests revealed operation differences in first grade $(t(66)=5.02, p<.01, d=0.68)$, but not in second grade $(t(66)=0.21, p=.83, d=0.03)$. The RT analyses showed no Operation $\mathrm{x}$ Time interaction $(F(1,66)=0.01, p=.92$, $\left.\eta_{p}^{2}=.00\right)$.

Children's single-digit arithmetic strategy use was examined by determining the frequency of fact retrieval (Table 2) and procedural strategies on the correctly solved items. The frequency of trials belonging to the "other" category was very low $(<0.5 \%)$ and these trials were further excluded. Frequencies of procedural strategy use were not reported, given that the frequencies of fact retrieval and procedural strategy use are about the inverse of each other as the "other" category was nearly zero.

A repeated measures ANOVA on the mean frequencies of fact retrieval was calculated with operation (addition vs. subtraction) and time (grade 1 vs. grade 2 ) as within-subject factors. This analysis revealed a main effect of operation $\left(F(1,66)=4.14, p=.046, \eta_{p}^{2}=\right.$ $.06)$, suggesting that fact retrieval was more frequently used during addition than during subtraction. There was a main effect of time $\left(F(1,66)=98.70, p<.01, \eta_{p}^{2}=.60\right)$ : children showed an increasing reliance on fact retrieval over developmental time. There was a significant Operation $\mathrm{x}$ Time interaction $\left(F(1,66)=14.27, p<.01, \eta^{2}=.18\right)$. Post-hoc $t$-tests revealed that the operation differences were significant in grade $1(t(66)=4.03, p<.01, d=0.40)$, but not in grade 2 $(t(66)=-0.43, p=.67, d=-0.06)$.

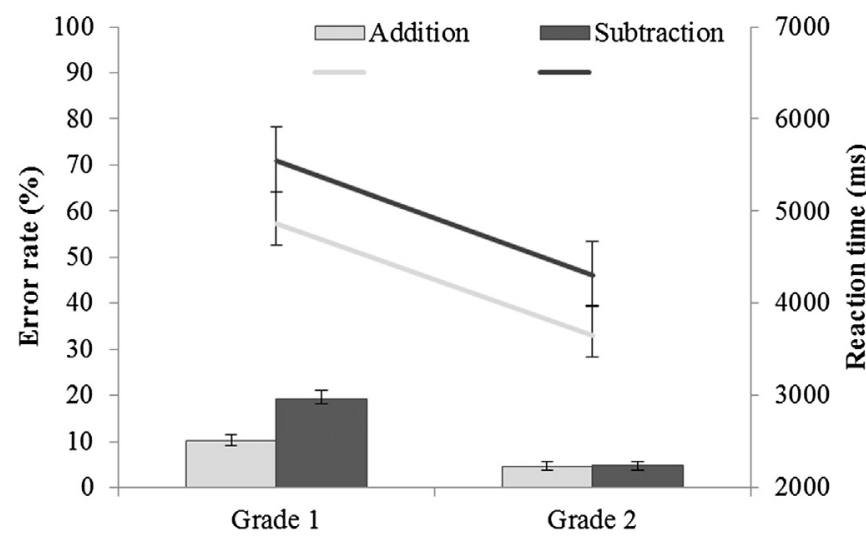

Fig. 1. Mean error rate (\% incorrectly solved problems) and RT on single-digit arithmetic per operation per time. Bars depict error rates on the left y-axis and lines represent RT on the right y-axis. Error bars represent $1 S E$ of the mean.
Table 2

Mean frequencies of the use of fact retrieval per operation per time $(n=67)$.

\begin{tabular}{lll}
\hline & Addition & Subtraction \\
\hline Grade 1 & $5.58(3.17)$ & $4.33(3.18)$ \\
Grade 2 & $8.57(2.60)$ & $8.72(2.83)$ \\
\hline
\end{tabular}

Note. Maximum possible $=14$. Standard deviations are presented between parentheses.

\subsection{Correlational analyses}

First, Pearson correlation coefficients were calculated to examine associations between cognitive skills, intellectual ability and preschool mathematical abilities (Table 3). Pearson correlational analyses were also used to explore predictive associations between cognitive skills and individual differences in single-digit arithmetic in the middle of first grade as well as the start of second grade (Table 4). Because subtraction and addition performance was strongly correlated (all $r s>.45$ ) and because the same pattern of predictive associations was observed for both operations, we averaged data across operations.

Additionally, predictive associations between cognitive skills and children's development in single-digit arithmetic were considered (Table 5). Arithmetic development was indexed by subtracting performance in grade 1 from performance in grade 2 . These difference scores showed that children became more accurate $(M=10.00 \% ; S D=10.56$; $t(66)=7.76, p<.01)$, faster $(M=-1233.15 \mathrm{~ms} ; S D=2763.84 ; t(66)=$ $-3.65, p<.01)$ and used more fact retrieval $(M=3.69 ; S D=3.04$; $t(66)=9.94, p<.01$ ), over developmental time.

\subsection{Regression analyses}

Regression analyses were conducted to determine the unique contribution of numerical processing measures to later individual differences and developmental changes in single-digit arithmetic. First, we verified whether each significant predictive association between a numerical processing measure and single-digit arithmetic remained when children's intellectual ability and preschool mathematical abilities were controlled for. Second, we tested the unique contribution of all the numerical processing measures that significantly predicted single-digit arithmetic, by entering them all simultaneously in a regression model.

\subsubsection{Single-digit arithmetic in grade 1}

Symbolic comparison accuracy uniquely predicted children's arithmetic accuracy $\left(\beta=.24, t=2.03, p<.05\right.$, unique $\left.R^{2}=.06\right)$ and RT $\left(\beta=-.44, t=-3.76, p<.01\right.$, unique $\left.R^{2}=.18\right)$. None of the other numerical processing measures emerged as unique predictors.

Digit naming RT, symbolic comparison accuracy and symbolic comparison RT were unique predictors of children's fact retrieval use. When these three measures were simultaneously entered into the regression model, only symbolic comparison RT remained significant $(\beta=-.32$, $t=-2.45, p<.05$, unique $\left.R^{2}=.07\right)$.

\subsubsection{Single-digit arithmetic in grade 2}

Nonsymbolic comparison accuracy was the only numerical processing measure that uniquely predicted children's arithmetic accuracy. Both digit naming RT and symbolic comparison RT significantly contributed to children's arithmetic RT. When exploring the relative contribution of these two measures, only symbolic comparison RT remained significant $\left(\beta=.28, t=1.99, p=.05\right.$, unique $\left.R^{2}=.06\right)$.

Digit naming RT, symbolic comparison RT, nonsymbolic comparison accuracy and nonsymbolic comparison RT were all significant predictors of fact retrieval. When entering these measures simultaneously into a model, only nonsymbolic comparison accuracy $(\beta=-.32, t=-2.45$, $p<.01$, unique $\left.R^{2}=.07\right)$ remained significant. It is important to point out that the three RT measures were highly correlated (see Table 3). To explore the effect of these intercorrelations, a series of additional 
Table 3

Associations between the measures collected at the start of first grade ( $n=67$ )

\begin{tabular}{|c|c|c|c|c|c|c|c|c|c|c|}
\hline & 1 & 2 & 3 & 4 & 5 & 6 & 7 & 8 & 9 & 10 \\
\hline \multicolumn{11}{|l|}{1 Digit naming ACC } \\
\hline 2 Digit naming RT & $-.60^{* *}$ & & & & & & & & & \\
\hline 3 Symbolic comparison ACC & $.34^{* *}$ & $-.38^{* *}$ & & & & & & & & \\
\hline 4 Symbolic comparison RT & $-.28^{*}$ & $.50^{* *}$ & .08 & & & & & & & \\
\hline 5 Nonsymbolic comparison ACC & $.26^{*}$ & -.18 & .13 & -.16 & & & & & & \\
\hline 6 Nonsymbolic comparison RT & -.09 & $.34^{* *}$ & .04 & $.67^{* *}$ & -.03 & & & & & \\
\hline 7 Verbal working memory & .20 & -.18 & .12 & -.08 & -.08 & .02 & & & & \\
\hline 8 Visuo-spatial short-term memory & -.07 & -.22 & .20 & $-.27^{*}$ & .03 & -.13 & .09 & & & \\
\hline 9 Processing speed & $-.35^{* *}$ & $.52^{* *}$ & -.12 & $.36^{* *}$ & .01 & .05 & -.15 & -.20 & & \\
\hline 10 Intellectual ability & .10 & .02 & .25 & .02 & .21 & .02 & .22 & .17 & .21 & \\
\hline 11 Preschool math & $.36^{* *}$ & $-.33^{* *}$ & .13 & $-.32^{* *}$ & .22 & -.12 & $.36^{* *}$ & $.27^{*}$ & -.13 & $.37^{* *}$ \\
\hline
\end{tabular}

Note. ACC $=$ Accuracy. $\mathrm{RT}=$ Reaction time. ${ }^{*} p<.05 .{ }^{* *} p<.01$.

regression analyses were conducted. First, digit naming RT, nonsymbolic comparison accuracy and nonsymbolic comparison RT were entered simultaneously in a model, revealing that only the two nonsymbolic measures remained significant. In the second model, symbolic comparison RT, nonsymbolic comparison accuracy and nonsymbolic comparison RT were entered. Nonsymbolic comparison accuracy remained a significant predictor of arithmetic fact retrieval, symbolic comparison RT became a marginally significant predictor, whereas the contribution of nonsymbolic RT was not significant. Third, a regression model was run with digit naming RT, symbolic comparison RT and nonsymbolic comparison accuracy. In this model only symbolic comparison RT and nonsymbolic comparison accuracy remained significant. Based on this additional series of regression analyses, we estimated a new model in which we considered nonsymbolic comparison accuracy $(\beta=.30$, $t=2.64, p<.05$, unique $\left.R^{2}=.08\right)$ and symbolic comparison $\mathrm{RT}(\beta=$ $.42, t=3.65, p<.01$, unique $R^{2}=.16$ ) as predictors of children's use of arithmetic fact retrieval. Both these measures emerged as significant predictors.

\subsubsection{Development in single-digit arithmetic from grade 1 to grade 2}

The numerical processing measures did not predict children's development in arithmetic accuracy. Symbolic comparison accuracy significantly predicted children's development in arithmetic RT $(\beta=.44$, $t=3.64, p<.01$, unique $R^{2}=.31$ ) and increasing reliance on arithmetic fact retrieval $\left(\beta=-.27, t=-2.18, p<.05\right.$, unique $R^{2}=.13$ ).

\subsubsection{The influence of non-numerical cognitive skills}

We performed an additional series of regression analyses in order to evaluate whether the numerical processing measures that emerged as unique predictors of future individual differences in single-digit arithmetic in the sections described above, remained after verbal working

Table 4

Predictive associations between cognitive skills and single-digit arithmetic per time $(n=$ 67).

\begin{tabular}{|c|c|c|c|c|c|c|}
\hline & \multicolumn{3}{|c|}{$\begin{array}{l}\text { Middle grade } 1 \\
\text { Single-digit arithmetic }\end{array}$} & \multicolumn{3}{|c|}{$\begin{array}{l}\text { Start grade } 2 \\
\text { Single-digit arithmetic }\end{array}$} \\
\hline & ACC & RT & $\begin{array}{l}\text { Fact } \\
\text { retrieval }^{\mathrm{a}}\end{array}$ & ACC & RT & $\begin{array}{l}\text { Fact } \\
\text { retrieval }^{\mathrm{a}}\end{array}$ \\
\hline Digit naming ACC & $.33^{* *}$ & -.14 & .17 & .11 & .21 & .19 \\
\hline Digit naming RT & $-.30^{*}$ & $.24^{*}$ & $-.39 * *$ & $-.26^{*}$ & $.33^{* *}$ & $-.31^{*}$ \\
\hline Symbolic comparison ACC & $.33^{* *}$ & $-.46^{* *}$ & $.36^{* *}$ & .10 & .00 & .03 \\
\hline Symbolic comparison RT & -.21 & .09 & $-.32^{* *}$ & -.23 & $.39 * *$ & $-.42^{* *}$ \\
\hline $\begin{array}{l}\text { Nonsymbolic comparison } \\
\text { ACC }\end{array}$ & $.27^{*}$ & -.10 & .05 & $.39^{* *}$ & .15 & $.36^{* *}$ \\
\hline Nonsymbolic comparison RT & -.03 & .13 & -.22 & -.04 & $.25^{*}$ & $-.37^{* *}$ \\
\hline Verbal working memory & .11 & .10 & -.02 & .05 & .02 & -.06 \\
\hline $\begin{array}{l}\text { Visuo-spatial short-term } \\
\text { memory }\end{array}$ & .15 & -.08 & .21 & .11 & .03 & .10 \\
\hline Processing speed & -.17 & .09 & -.15 & -.09 & $.31^{*}$ & -.14 \\
\hline
\end{tabular}

Note. ACC $=$ Accuracy. $\mathrm{RT}=$ Reaction time. ${ }^{\text {a }}$ Frequency of fact retrieval use ${ }^{*} p<.05$ ** $p<.01$. memory, visuo-spatial short-term memory and processing speed were taken into account. Table 6 gives an overview of the numerical processing predictors with unique contributions to future individual and developmental differences in single-digit arithmetic after taking into account the above mentioned additional measures.

The analyses indicate that numerical processing measures that uniquely predicted children's future single-digit arithmetic continued to be significant predictors after verbal working memory, visuo-spatial short-term memory and general processing speed were additionally controlled for, except for children's arithmetic accuracy in the middle of first grade that was no longer predicted by symbolic comparison accuracy. Symbolic comparison accuracy became a marginally significant predictor of children's arithmetic fact development.

\section{Discussion}

While recent longitudinal evidence suggests that numerical processing skills predict children's future general mathematics achievement (e.g., De Smedt et al., 2013, for a review) it remains largely unexplored whether this predictive association also applies to more specific mathematical skills, such as arithmetic fact development. Importantly, it remains to be verified whether such predictive associations remain when other factors that have been shown to contribute to individual differences in arithmetical competence are controlled for.

The present data provide longitudinal evidence that children's numerical processing skills at the start of formal schooling are predictively related to their future single-digit arithmetic and reliance on arithmetic fact retrieval. These predictive associations are independent of children's intellectual ability, preschool mathematical abilities, verbal working memory, visuo-spatial short-term memory and processing speed.

Our findings are in agreement with previous longitudinal studies that observed predictive associations between symbolic numerical

Table 5

Predictive associations between cognitive skills and children's single-digit arithmetic development $(n=67)$.

\begin{tabular}{llll}
\hline & \multicolumn{3}{l}{$\begin{array}{l}\text { Grade 1 to grade 2 development } \\
\text { in single-digit arithmetic }\end{array}$} \\
\cline { 2 - 4 } & ACC & RT & Fact retrieval \\
\hline Digit naming ACC & $-.30^{*}$ & -.02 & -.02 \\
Digit naming RT & .18 & .02 & .13 \\
Symbolic comparison ACC & $-.30^{*}$ & $.44^{* *}$ & $-.32^{* *}$ \\
Symbolic comparison RT & .10 & .21 & -.02 \\
Nonsymbolic comparison ACC & -.09 & -.02 & .23 \\
Nonsymbolic comparison RT & .01 & .06 & -.07 \\
Verbal working memory & -.10 & -.08 & -.03 \\
Visuo-spatial short-term memory & -.10 & .06 & -.13 \\
Processing speed & .13 & .15 & .03 \\
\hline
\end{tabular}

Note. ACC $=$ Accuracy. $\mathrm{RT}=$ Reaction time. The variables accuracy, reaction time and fact retrieval represent change in single-digit arithmetic between grade 1 to grade $2 .{ }^{*} p<$ $05^{* *} p<.01$. 


\section{Table 6}

Overview of numerical processing predictors with unique contributions to single-digit arithmetic after taking into account intellectual ability, preschool mathematical abilities, verbal working memory, visuo-spatial short-term memory and processing speed.

\begin{tabular}{|c|c|c|c|c|}
\hline $\begin{array}{l}\text { Single-digit } \\
\text { arithmetic }\end{array}$ & $\begin{array}{l}\text { Numerical processing } \\
\text { predictor }\end{array}$ & $\beta$ & $t$ & unique $R^{2}$ \\
\hline \multicolumn{5}{|l|}{ Middle grade 1} \\
\hline ACC & Symbolic comparison ACC & .21 & $1.69^{\circ}$ & .04 \\
\hline RT & Symbolic comparison ACC & -.45 & $-3.76^{* *}$ & .18 \\
\hline Fact retrieval & Symbolic comparison RT & -.32 & $-2.53^{*}$ & .08 \\
\hline \multicolumn{5}{|l|}{ Start grade 2} \\
\hline ACC & Nonsymbolic comparison ACC & .36 & $2.85^{* *}$ & .12 \\
\hline RT & Symbolic comparison RT & .30 & $2.27^{*}$ & .07 \\
\hline \multirow[t]{2}{*}{ Fact retrieval } & Nonsymbolic comparison ACC & .27 & $2.35^{*}$ & .07 \\
\hline & Symbolic comparison RT & -.41 & $-3.28^{* *}$ & .13 \\
\hline \multicolumn{5}{|l|}{ Development } \\
\hline RT & Symbolic comparison ACC & .48 & $3.89 * *$ & .20 \\
\hline Fact retrieval & Symbolic comparison ACC & -.26 & $-1.96^{\circ \circ}$ & .10 \\
\hline
\end{tabular}

Note. ACC $=$ Accuracy. $\mathrm{RT}=$ Reaction time. Frequency of fact retrieval use. ${ }^{*} p<.05$. ${ }^{* *} p<.01{ }^{\circ} p=.10{ }^{\circ}{ }^{\circ} p=.06$.

processing skills and future general mathematics performance (e.g., Bartelet et al., 2014; De Smedt et al., 2009; Sasanguie et al., 2012, 2013). Our data go beyond the previous ones by showing that children's digit naming as well as symbolic numerical magnitude processing skills are predictively associated with their development of single-digit arithmetic. When evaluating the unique contribution of both these symbolic processing measures, symbolic numerical magnitude comparison performance turned out to be the best cognitive predictor of future individual differences and developmental changes in children's single-digit arithmetic. This suggests that children who are at primary school entrance more proficient at processing symbolic magnitudes will perform better on single-digit arithmetic in the early years of primary school.

Consistent with Desoete et al. (2010), we found that nonsymbolic numerical magnitude comparison performance was predictively related to arithmetic proficiency in second grade, although such predictive association was not observed for the middle of first grade. It is important to emphasize that there are inconsistent results on the association between nonsymbolic numerical magnitude processing and mathematical competence (e.g. De Smedt et al., 2013). This inconsistency might be explained by methodological issues in the design of stimuli in nonsymbolic numerical magnitude comparison tasks. Gebuis and Reynvoet (2012a) showed that the decision on the more numerous dot array is influenced by numerical as well as visual characteristics of the dot array, even if one tries to control for these visual parameters, which might facilitate or interfere with the decision process. Gilmore et al. (2013) further explored this issue and showed that only performance on incongruent trials, i.e. those dot arrays in which the more numerous array consists of visually smaller dots and a smaller area, of the nonsymbolic numerical magnitude comparison task correlated with mathematical competence. As a consequence, on these trials children have to inhibit visual characteristics but selectively attend to the numerical characteristics of the dot arrays. These trials reflect inhibitory skills rather than numerical processing and this was subsequently confirmed when showing that the association between incongruent trials and mathematical competence disappeared when inhibition skills were additionally accounted for. This finding is in agreement with studies that demonstrated strong associations between inhibition skills and mathematical competence (e.g., Blair \& Razza, 2007; Scüzs, Devine, Soltesz, Nobes, \& Gabriel, 2013). Individual differences in inhibition skills might explain why children's nonsymbolic numerical magnitude comparison performance emerged as a predictor of second grade arithmetic performance. It might be that at this point in development, when children have developed a set of problem-answer associations, successful arithmetic performance also depends on inhibiting the incorrect answer from long-term memory (e.g., Geary, Hoard, \& Bailey, 2012). Further research is however necessary to investigate this possibility.
The current study also revealed that early numerical processing skills continued to predict future individual differences and developmental changes in single-digit arithmetic above verbal working memory, visuospatial short-term memory and processing speed. Surprisingly, children's verbal working memory and visuospatial short-term memory were not longitudinally associated with single-digit arithmetic. These findings are in line with some published studies (e.g., Andersson, 2008; Rasmussen \& Bisanz, 2005), but they differ from others (e.g., Andersson \& Lyxell, 2007; Jarvis \& Gathercole, 2003; Lefevre et al., 2013; Krajewski \& Schneider, 2009). The absence of associations between arithmetic and the included non-numerical cognitive skills might be due to our restricted focus on single-digit arithmetic in the number domain up to 10 . This is supported by the meta-analysis of Friso-van den Bos et al. (2013) who concluded that children rely on verbal working memory and visuo-spatial short-term memory to a larger extent when solving more complex mathematical tasks (e.g. general standardized achievement tests), than when performing on tests measuring one specific type of mathematical skill. Our data are in line with this as the measures of verbal working memory and visual-spatial short-term memory were significantly associated with children's preschool mathematical abilities.

The longitudinal design of the study and the additional control for preschool mathematical abilities provide strong evidence for the idea that proficient numerical processing skills precede children's development of single-digit arithmetic in the early years of primary school. It is important to point out that this conclusion only applies to children's development of basic arithmetic in the number domain up to 10 and further research is needed to extend this research to other components of arithmetic, i.e., multi-digit arithmetic, calculation principles, place value, estimation, applying arithmetic for solving word problems (Dowker, 2008). We also would like to emphasize that the current sample remains rather restricted, given that the children came from middleto upper middle-class neighborhoods. Future studies should therefore include more varied samples in terms of social background. Such studies should also consider children with mathematical difficulties. Finally, in view of the large differences between countries in the age at which formal mathematics education starts, it might be fruitful to investigate the association between numerical processing and arithmetic in crosscultural studies with children from different educational systems.

The current data do not allow us to establish bidirectional connections between numerical processing and single-digit arithmetic development. This calls for an extensive longitudinal data collection, which should preferably start before children receive formal mathematics instruction, and in which numerical processing tasks as well as different measures of arithmetic should be administered at different measurement occasions. This will allow us to discover whether the associations between numerical processing and children's arithmetic competence change over developmental time (e.g., Cowan et al., 2011; Dowker, 2005). Future research should also investigate whether other tasks that have been used to evaluate numerical processing, such as number line estimation (e.g., Booth \& Siegler, 2006) or counting (LeFevre et al., 2006) are unique predictors of single-digit arithmetic development. Such research should also consider other non-numerical cognitive skills than those investigated in the current study. For example, it might be interesting to examine how visual processing (e.g., Gebuis \& Reynvoet, 2012b) as well as inhibition (e.g., Gilmore et al., 2013) might explain the association between nonsymbolic numerical magnitude comparison performance and arithmetic.

\section{References}

Andersson, U. (2008). Working memory as a predictor of written arithmetic skills in children: The importance of executive functions. British Journal of Educational Psychology, 78, 181-203. http://dx.doi.org/10.1348/000709907X209854

Andersson, U., \& Lyxell, B. (2007). Working memory deficit in children with mathematical problems: A general or specific deficit? Journal of Experimental Child Psychology, 96 197-228. http://dx.doi.org/10.1016/j.jecp.2006.10.001. 
Aunola, K., Leskinen, E., Lerkkanen, M. K., \& Nurmi, J. E. (2004). Developmental dynamics of math performance from preschool to Grade 2. Journal of Educational Psychology, 96, 699-713. http://dx.doi.org/10.1037/0022-0663.96.4.699.

Bailey, D. H., Littlefield, A., \& Geary, D. C. (2012). The codevelopment of skill at and preference for use of retrieval-based processes for solving addition problems: Individual and sex differences from first to sixth grades. Journal of Experimental Child Psychology, 113, 78-92. http://dx.doi.org/10.1016/j.jecp.2012.04.014.

Barrouillet, P., \& Lépine, R. (2005). Working memory and children's use of retrieval to solve addition problems. Journal of Experimental Child Psychology, 91, 183-204. http://dx.doi.org/10.1016/j.jecp.2005.03.002.

Barrouillet, P., Mignon, M., \& Thevenot, C. (2008). Strategies in subtraction problem solving in children. Journal of Experimental Child Psychology, 99, 233-251. http://dx.doi. org/10.1016/j.jecp.2007.12.001.

Bartelet, D., Vaessen, A., Blomert, L., \& Ansari, D. (2014). What basic number processing measures in kindergarten explain unique variability in first-grade arithmetic proficiency? Journal of Experimental Child Psychology, 117, 12-28. http://dx.doi.org/10. 1016/j.jecp.2013.08.010

Barth, H., Beckmann, L., \& Spelke, E. (2008). Nonsymbolic, approximate arithmetic in children: Abstract addition prior to instruction. Developmental Psychology, 44 1466-1477. http://dx.doi.org/10.1037/a0013046.

Blair, C., \& Razza, R. P. (2007). Relating effortful control, executive function, and false belief understanding to emerging math and literacy ability in kindergarten. Child Development, 78, 647-663. http://dx.doi.org/10.1111/j.1467-8624.2007.01019.x.

Booth, J. L., \& Siegler, R. S. (2006). Developmental and individual differences in pure numerical estimation. Developmental Psychology, 42, 189-201. http://dx.doi.org/10. 1037/0012-1649.41.6.189.

Bull, R., Espy, K. A., \& Wiebe, S. A. (2008). Short-term memory, working memory, and executive functioning in preschoolers: Longitudinal predictors of mathematica achievement at 7 years. Developmental Neuropsychology, 33, 205-228. http://dx.doi. org/10.1080/87565640801982312.

Caviola, S., Mammarella, I. C., Cornoldi, C., \& Lucangeli, D. (2012). The involvement of working memory in children's exact and approximate mental addition. Journal of Experimental Child Psychology, 112, 141-160. http://dx.doi.org/10.1016/j.jecp.2012. 02.005 .

Cowan, R., Donlan, C., Shepherd, D. L., Cole-Fletcher, R., Saxton, M., \& Hurry, J. (2011) Basic calculation proficiency and mathematics achievement in elementary schoo children. Journal of Educational Psychology, 103, 786-803. http://dx.doi.org/10.1037/ a0024556.

De Smedt, B., Noël, M., Gilmore, C., \& Ansari, D. (2013). How do symbolic and nonsymbolic numerical magnitude processing skills relate to individual differences in children's mathematical skills? A review of evidence from brain and behavior. Trends in Neuroscience and Education, 2, 48-55. http://dx.doi.org/10.1016/j.tine 2013.06.001.

De Smedt, B., Verschaffel, L., \& Ghesquière, P. (2009). The predictive value of numerical magnitude comparison for individual differences in mathematics achievement. Journal of Experimental Child Psychology, 103, 469-479. http://dx.doi.org/10.1016/j. jecp.2009.01.010

Desoete, A., Ceulemans, A., De Weerdt, F., \& Pieters, S. (2010). Can we predict mathematical learning disabilities from symbolic and non-symbolic comparison tasks in kindergarten? Findings from a longitudinal study. British Journal of Educational Psychology, 82, 64-81. http://dx.doi.org/10.1348/2044-8279.002002.

Dowker, A. (2005). Individual differences in arithmetic. Implications for psychology, neuroscience and education. Hove, UK: Psychology Press.

Dowker, A. (2008). Individual differences in numerical abilities in preschoolers Developmental Science, 11, 650-654. http://dx.doi.org/10.1111/j.1467-7687.2008. 00713.x.

Dudal, P. (2000). Leerlingvolgsysteem: Wiskunde-Toetsen 1-2-3 Basisboek [Student monitoring system: Mathematics-Tests 1-2-3 manual]. Leuven, Belgium: Garant.

Duncan, G. J., Dowsett, C. J., Claessens, A., Magnuson, K., Huston, A. C., Klebanov, P., et al (2007). School readiness and later achievement. Developmental Psychology, 43 1428-1446. http://dx.doi.org/10.1037/0012-1649.43.6.1428.

Friso-van den Bos, I., van der Ven, S. H. G., Kroesbergen, E. H., \& van Luit, J. E. H. (2013). Working memory and mathematics in primary school children: A meta-analysis. Educational Research Review, 10, 29-44. http://dx.doi.org/10.1016/j.edurev.2013.05. 003.

Fuchs, L. S., Geary, D. C., Fuchs, D., Compton, D. L., \& Hamlett, C. L. (2014). Sources of individual differences in emerging competence with numeration understanding versus multidigit calculation skill. Journal of Educational Psychology, 106, 482-498. http:/ dx.doi.org/10.1037/a0034444.

Geary, D. C. (2013). Early foundations for mathematics learning and their relations to learning disabilities. Current Directions in Psychological Science, 22, 23-27. http://dx. doi.org/10.1177/0963721412469398.

Geary, D. C., Hoard, M. K., \& Bailey, D. H. (2012). Fact retrieval deficits in low achieving children and children with mathematical learning disability. Journal of Learning Disabilities, 45, 291-307. http://dx.doi.org/10.1177/0022219410392046.

Gebuis, T., \& Reynvoet, B. (2012a). The interplay between nonsymbolic number and its continuous visual properties. Journal of Experimental Psychology: General, 141 642-648. http://dx.doi.org/10.1037/a0026218.

Gebuis, T., \& Reynvoet, B. (2012b). The role of visual information in numerosity estimation. PLoS ONE, 7, e37426. http://dx.doi.org/10.1371/journal.pone.0037426.

Gilmore, C., Attridge, N., Clayton, S., Cragg, L., Johnson, S., Marlow, N., et al. (2013). Individual differences in inhibitory control, not non-verbal number acuity, correlate with mathematics achievement. PLoS ONE, 8, e67374. http://dx.doi.org/10.1371/ journal.pone.0067374.

Hecht, S. A., Torgesen, J. K., Wagner, R. K., \& Rashotte, C. A. (2001). The relations between phonological processing abilities and emerging individual differences in mathematical computation skills: A longitudinal study from second to fifth grades. Journal of Experimental Child Psychology, 79, 192-227. http://dx.doi.org/10.1006/ jecp.2000.2586.

Holmes, J., Adams, J. W., \& Hamilton, C. J. (2008). The relationship between visuospatial sketchpad capacity and children's mathematical skills. European Journal of Cognitive Psychology, 20, 272-289. http://dx.doi.org/10.1080/09541440701612702.

Imbo, I., \& Vandierendonck, A. (2007a). The role of phonological and executive working memory resources in simple arithmetic strategies. European Journal of Cognitive Psychology, 19, 910-933. http://dx.doi.org/10.1080/09541440601051571.

Imbo, I., \& Vandierendonck, A. (2007b). The development of strategy use in elementary school children: Working memory and individual differences. Journal of Experimental Child Psychology, 96, 284-309. http://dx.doi.org/10.1016/j.jecp.2006.09. 001.

Jarvis, H. E., \& Gathercole, S. E. (2003). Verbal and non-verbal working memory and achievements on National Curriculum tests at 11 and 14 years of age. Educational and Child Psychology, 20, 123-140.

Jordan, J. A., Mulhern, G., \& Wylie, G. (2009). Individual differences in trajectories of arithmetical development in typically achieving 5- to 7-year-olds. Journal of Experimental Child Psychology, 103, 455-468. http://dx.doi.org/10.1016/j.jecp.2009.01.011.

Kilpatrick, J., Swafford, J., \& Findell, B. (2001). Adding it up: Helping children learn mathematics. Washington, DC: National Academies Press.

Koponen, T., Aunola, K., Ahonen, T., \& Nurmi, J. E. (2007). Cognitive predictors of singledigit and procedural calculation and their covariation with reading skill. Journal of Experimental Child Psychology, 97, 220-241. http://dx.doi.org/10.1016/j.jecp.2007.03. 001

Krajewski, K., \& Schneider, W. (2009). Exploring the impact of phonological awareness, visual-spatial working memory, and preschool quantity-number competencies on mathematics achievement in elementary school: Findings from a 3-year longitudinal study. Journal of Experimental Child Psychology, 103, 516-531. http://dx.doi.org/10. 1016/j.jecp.2009.03.009.

Lefevre, J., Berrigan, L., Vendetti, C., Kamawar, D., Bisanz, J., Skwarchuk, S., et al. (2013). The role of executive attention in the acquisition of mathematical skills for children in grades 2 through 4. Journal of Experimental Child Psychology, 114, 243-261. http://dx.doi.org/10.1016/j.jecp.2012.10.005.

Lefevre, J., Sadesky, G. S., \& Bisanz, J. (1996). Selection of procedures in mental addition: Reassessing the problem size effect in adults. Journal of Experimental Psychology, 22, 216-230. http://dx.doi.org/10.1037//0278-7393.22.1.216.

LeFevre, J., Smith-Chant, B. L., Fast, L., Skwarchuk, S., Sargla, E., Arnup, J. S., et al. (2006). What counts as knowing? The development of conceptual and procedural knowledge of counting from kindergarten through Grade 2. Journal of Experimental Child Psychology, 93, 285-303. http://dx.doi.org/10.1016/j.jecp.2005.11.002.

Libertus, M. E., Feigenson, L., \& Halberda, J. (2013a). Is approximate number precision a stable predictor of math ability? Learning and Individual Differences, 25, 126-133. http://dx.doi.org/10.1016/j.lindif.2013.02.001.

Libertus, M. E., Feigenson, L., \& Halberda, J. (2013b). Numerical approximation abilities correlate with and predict informal but not formal mathematics abilities. Journal of Experimental Child Psychology, 116, 829-838. http://dx.doi.org/10.1016/j.jecp.2013. 08.003

Linsen, S., Verschaffel, L., Reynvoet, B., \& De Smedt, B. (2014). The association between children's numerical magnitude processing and mental multi-digit subtraction. Acta Psychologica, 145, 75-83. http://dx.doi.org/10.1016/j.actpsy.2013.10.008.

Mazzocco, M. M. M., Feigenson, L., \& Halberda, J. (2011). Preschooler's precision of the approximate number system predicts later school mathematics performance. PLOS ONE, 6. e23749. http://dx.doi.org/10.1371/journal.pone.0023749.

Piazza, M., Izard, V., Pinel, P., Le Bihan, D., \& Dehaene, S. (2004). Tuning curves for approximate numerosity in the human intraparietal sulcus. Neuron, 44, 547-555. http://dx. doi.org/10.1016/j.neuron.2004.10.014.

Pickering, S., \& Gathercole, S. (2001). Working Memory Test Battery for Children (WMTB-C). London: Psychological Corporation.

Rasmussen, C., \& Bisanz, J. (2005). Representation and working memory in early arithmetic. Journal of Experimental Child Psychology, 91, 137-157. http://dx.doi.org/10. 1016/j.jecp.2005.01.004.

Raven, J. C., Court, J. H., \& Raven, J. (1992). Standard progressive matrices. Oxford: Oxford Psychologists Press.

Resnick, L. B. (1989). Developing mathematical knowledge. American Psychologist, 44, 162-169. http://dx.doi.org/10.1037//0003-066X.44.2.162.

Sasanguie, D., Göbel, S. M., Moll, K., Smets, K., \& Reynvoet, B. (2013). Approximate number sense, symbolic number processing or number-space mappings: what underlies mathematics achievement? Journal of Experimental Child Psychology, 114, 418-431. http://dx.doi.org/10.1016/j.jecp.2012.10.012.

Sasanguie, D., Van den Bussche, E., \& Reynvoet, B. (2012). Predictors for mathematics achievement? Evidence from a longitudinal study. Mind, Brain, and Education, 6, 119-128. http://dx.doi.org/10.1111/j.1751-228X.2012.01147.x.

Schneider, W., Eschmann, A., \& Zuccolotto, A. (2002). E-Prime reference guide. Pittsburgh, PA: Psychology Software Tools.

Scüzs, D., Devine, A., Soltesz, F., Nobes, A., \& Gabriel, F. (2013). Developmental dyscalculia is related to visuo-spatial memory and inhibition impairment. Cortex, 49, 2674-2688. http://dx.doi.org/10.1016/j.cortex.2013.06.007.

Siegler, R. S. (1996). Emerging minds: The process of change in children's thinking. New York, NY: Oxford University Press.

Siegler, R. S., \& Shrager, J. (1984). Strategy choice in addition and subtraction: How do children know what to do? In C. Sophian (Ed.), Origins of cognitive skills (pp. 229-293). Hillsdale, NJ: Erlbaum.

Siegler, R. S., \& Stern, E. (1998). Conscious and unconscious strategy discoveries: A microgenetic analysis. Journal of Experimental Psychology, 127, 377-397. http://dx. doi.org/10.1037//0096-3445.127.4.377. 
Torbeyns, J., Verschaffel, L., \& Ghesquière, P. (2004). Strategic aspects of simple addition and subtraction: The influence of mathematical ability. Learning and Instruction, 14, 177-195. http://dx.doi.org/10.1016/j.learninstruc.2004.01.003.

van den Bos, K. P., Zijlstra, B. J. H., \& Van den Broeck, W. (2003). Specific relations between alphanumeric-naming speed and reading speeds of monosyllabic and multisyllabic words. Applied PsychoLinguistics, 24, 407-430. http://dx.doi.org/10. 1017/S0142716403000213.
Vanbinst, K., Ghesquière, P., \& De Smedt, B. (2012). Numerical magnitude representations and individual differences in children's arithmetic strategy use. Mind, Brain, and Education, 6, 129-136. http://dx.doi.org/10.1111/j.1751-228X.2012.01148.x.

Xenidou-Dervou, I., van Lieshout, E. C. D. M., \& van der Schoot, M. (2013). Working memory in nonsymbolic approximate arithmetic processing: A dual-task study with preschoolers. Cognitive Science, 38, 101-127. http://dx.doi.org/10.1111/cogs.12053. 